\title{
Progress in the esophagogastric anastomosis and the challenges of minimally invasive thoracoscopic surgery
}

\section{Luigi Bonavina}

Division of General and Foregut Surgery, Department of Biomedical Sciences for Health, University of Milan, IRCCS Policlinico San Donato, San Donato Milanese (Milano), Italy

Correspondence to: Prof. Luigi Bonavina. Division of General and Foregut Surgery, Department of Biomedical Sciences for Health, University of Milan, IRCCS Policlinico San Donato, Piazza Malan 2, 20097 San Donato Milanese (Milano), Italy. Email: Luigi.bonavina@unimi.it.

\begin{abstract}
The esophagogastric anastomosis is most commonly performed to restore digestive tract continuity after esophagectomy for cancer. Despite a long history of clinical research and development of high-tech staplers, this procedure is still feared by most surgeons and associated with a $10 \%$ leakage rate. Among specific factors that may contribute to failure of the esophageal anastomosis are the absence of serosa layer, longitudinal orientation of muscle fibers, and ischemia of the gastric conduit. It has recently been suggested that the gut microbiome may influence the healing process of the anastomosis through the presence of collagenolytic bacterial strains, indicating that suture breakdown is not only a matter of collagen biosynthesis. The esophagogastric anastomosis can be performed either in the chest or neck, and can be completely hand-sewn, completely stapled (circular or linear stapler), or semi-mechanical (linear stapler posterior wall and hand-sewn anterior wall). Because of the lack of randomized clinical trials, no conclusive evidence is available, and the debate between the hand-sewn and the stapling technique is still ongoing even in the present era of robotic surgery. Centralization of care has improved the overall postoperative outcomes of esophagectomy, but the esophagogastric anastomosis remains the Achille's heel of the procedure. More research and network collaboration of experts is needed to improve safety and clinical outcomes.
\end{abstract}

Keywords: Esophagectomy; esophagogastric anastomosis; anastomotic leak; anastomotic stricture; circular stapler; linear stapler

Submitted Jan 13, 2020. Accepted for publication Feb 28, 2020.

doi: $10.21037 /$ atm.2020.03.66

View this article at: http://dx.doi.org/10.21037/atm.2020.03.66

The esophagogastric anastomosis represents a central part of the esophagectomy for cancer and contributes to the significant short- and long-term morbidity and mortality of this operation. Leakage, the most feared complication, has an average incidence rate of $10 \%$ and is associated with a 3 -fold increase in mortality, prolonged hospital stay, delayed oral feeding, risk of reintervention, decrease of overall and disease-free survival, and increased risk of recurrence $(1,2)$. The 1-year cumulative probability of anastomotic stricture is in the range of $12 \%$ to $33 \%$ (3), but in most patients this complication resolves with endoscopic dilatation and longterm proton-pump inhibitor therapy. With the increasing use of minimally invasive techniques and robotics in esophageal surgery, the intrathoracic esophagogastric anastomosis at the apex of the right chest has become the real challenge and surgeons are required to adapt to the prone or semiprone patient's decubitus and overcome the technical limitations imposed by trocars and rigidity of chest wall (4). Therefore, in an effort to standardize the procedure and minimize the potential for complications, a revisitation of the anastomotic techniques has occurred and the old debate on the use of hand-sewn versus mechanical sutures resumed $(5,6)$.

\section{Historical background}

The first esophageal resection with anastomosis was 
performed by Czerny in 1877. The first esophageal resection and esophagogastrostomy via a right thoracotomy and laparotomy was performed by Ivor Lewis in 1946 (7), and at that time the hand-sewn anastomosis was the only option for esophageal reconstruction. The first staplers enabling to perform a circular esophageal anastomosis were developed in the 1950s at the Scientific Research Institute for Experimental surgical Apparatus and Instruments in Moscow. Further experimental work, design, and clinical application of stapling instruments was made possible by Steichen and Ravitch in the United States $(8,9)$. In Europe, Féketé (10) and Peracchia (11) were early adopters of the circular stapling technique, and a semi-mechanical esophagogastric anastomosis using an endoscopic linear stapler was described by Collard in the late 1990s (12).

\section{Diagnosis and classification of anastomotic leak}

Early diagnosis of anastomotic leakage before clinically overt presentation and better perioperative care have significantly reduced the mortality related to leaks over the last decade. Levels of drain amylase or serum C-reactive protein may be predictive of the complication and may alert the surgeon to delay oral feeding (13). Endoscopy performed by an expert physician at low insufflation pressure is safe and feasible when there is a suspicion of anastomotic leak or ischemia of the gastric conduit (14). In general, the therapeutic paradigm has changed from reoperation to endoscopic therapy (stent, endosponge) combined with percutaneous management of para-anastomotic collections (15). Importantly, a new classification of anastomotic leakages provides a uniform reference and a "common language" that can guide the therapy algorithm (16).

\section{Pathophysiology of anastomotic healing and prevention of leakage}

In 1923, Miller and Andrus first demonstrated the mechanical strength of the esophageal submucosa in holding a suture and showed the feasibility of the esophagogastric anastomosis (17). The healing process of esophageal anastomosis is similar to that observed in other tissues and consists of three phases: inflammation (day $0-4$ ), proliferation (day 5-10), and remodeling (>day 10). According to classical research studies (18), the maximal strength of a wound is approached between 10 and 14 days. Postlethwait et al. investigated the relative strength of manually performed esophageal anastomoses in mongrel dogs. The esophagogastric anastomosis showed good immediate strength which increased at 6 hours and reached the nadir at 4 days. However, the mechanical strength of the esophagogastric anastomosis was lower compared to endto-end esophageal and to end-to-end enteric anastomoses both at 8 and 12 days (19).

It has recently been speculated that the microbiome may influence the healing process of the anastomosis. A systematic review of 8 randomized clinical trials including 1,668 patients found that the rate of anastomotic leakage rate was significantly lower in patients who had perioperative oral decontamination of the digestive tract compared to controls who received systemic antibiotic prophylaxis alone. Oral decontamination reduced the risk of anastomotic leakage without difference in effect between upper and lower gastrointestinal surgery (20). More recent experimental data suggest that the proinflammatory reaction following surgical injury may shift the phenotype of intestinal pathogens to increase collagenase production and matrix metalloproteinase activation. Therefore, a more invasive collagenolytic and cytotoxic phenotype can cause anastomotic break-down, indicating that failure of anastomotic healing is not only a matter of collagen biosynthesis (21). A prospective study on 55 esophagectomy patients found a significantly greater variance in the microbiome diversity in oral and gastric samples of patients who had a leak compared to those without leaks (22). Also, a recent study found that lowfat/high fiber diet prehabilitation can reverse the adverse effect of a high-fat diet on anastomotic healing in mice by restoring the Bacteroidetes in the colonic lumen (23). If confirmed in larger studies, this may suggest that the oral and upper gastrointestinal microbiome are implicated in the pathogenesis of anastomotic leakage, and that manipulation of microbiome may possibly be used in the future to decrease the incidence of anastomotic leakage.

Prevention of anastomotic leakage has been the main focus of research for several decades. An approach to improve blood supply at the anastomotic site has been the technique of "supercharging" the gastric conduit. Nagawa et al. (24) and Murakami et al. (25) performed microvascular augmentation of the gastric conduit and noted no leaks compared to historical controls. Akijama et al. first introduced the concept of gastric ischemic pre-conditioning to improve blood flow at the anastomotic site. Preoperative angiographic embolization of left gastric, right gastric, and splenic arteries followed a few days later by esophagectomy 
and esophagogastrostomy reduced blood flow at the apex of gastric conduit by one third from baseline and also reduced the incidence of anastomotic leak compared to the control group (26). Subsequent investigators revisited the concept of ischemic preconditioning and performed laparoscopic ligation of the left gastric vessels followed by definitive esophagectomy as a second-stage procedure $(27,28)$.

It has been long proposed that wrapping the anastomosis with omentum (10) and using fibrin glue (29) may help to promote sealing and protect from leakage, but the grade of evidence from the literature is low. Intraoperative preemptive application of endoscopic vacuum therapy to stimulate granulation tissue at the anastomotic site and reduce anastomotic leak rate has been recently tested. In a recent case-series, the VAC device was applied in 19 patients immediately after completion of the esophagogastrostomy and removed at a median of 5 days postoperatively. Only one contained anastomotic leak occurred and healed after a second course of treatment (30).

Finally, malfunction of surgical staplers may cause anastomotic leakage, although many adverse events are not reported to the Manufacturer and User Facility Device Experience (MAUDE) database and therefore the true incidence stapler failure is unknown and probably underestimated $(31,32)$. While it is difficult to attribute stapler malfunction to instrument failure rather than to user error, the number of product recalls argues that staplers have an inherent potential to fail and that reclassification of internal surgical staplers from low risk (class I) devices to moderate-risk (class II) should be considered (33).

\section{Techniques of intrathoracic and cervical anastomosis: tips and tricks}

An esophagogastric anastomosis can be performed using a variety of techniques. Because of the lack of randomized clinical trials, no conclusive evidence is available regarding the risk of leakage, and the debate between the handsewn and the stapling technique is still ongoing. The semimechanical anastomosis, by enlarging the cross-sectional area, has the potential to prevent postoperative anastomotic stricture (34-36). Performing the esophagogastric anastomosis in the neck may be an option to simplify the semi-mechanical anastomosis. However, the cervical anastomosis carries a higher risk of recurrent nerve injury and, with the current epidemiological shift toward a greater prevalence of adenocarcinoma, an intrathoracic anastomosis is biologically more plausible $(37,38)$.

To perform an intrathoracic mechanical anastomosis, division of the esophagus should be done just at the level of the arch of the azygos vein. When a classical anastomosis is chosen, it is preferable to perform a horizontal esophagotomy in order to keep the esophagus in traction rather than divide it right away. The easiest way to insert the stapler anvil in the esophageal lumen is to attach a 2-0 prolene suture to the anvil rod and, by reverse puncture from inside the lumen, retrieving the rod outside the esophageal wall. At this point, a linear stapler is applied just below the exit site of the suture and the esophagus is transected. This avoids the need of a purse-string suture that may prove difficult in patients with a narrow upper mediastinum. An alternative technique is the use of a transoral delivery system $\left(\mathrm{Orvil}^{\mathrm{TM}}{ }^{\mathrm{T}}\right.$ ). The first step of the procedure is to transect the esophagus with a linear stapler. The angle of stapler insertion through the trocar site is important to obtain a section which is perpendicular to the vertebral plane. The Orvil accessory is introduced by mouth, with the pretilted anvil attached to a tube which is retrieved through a small incision above the stapled esophagus $(39,40)$. Use of the Orvil technique during minimally invasive surgery has not proven consistently straightforward due difficulties in the alignment of the center rod, slippage of the conduit off the stapler, and disengagement of the stapler pin. This may prevent from docking the EEA-XL stapler with the anvil $(41,42)$. Once the anvil is secured in the esophageal stump, the gastric tube is delivered through the hiatus in the chest, with care to prevent rotation. The $25 \mathrm{~mm}$ circular stapler is introduced through a mini-thoracotomy protected by an Alexis device and a glove to maintain the pneumothorax. The gastrotomy site is closed with a linear stapler. Whenever possible, omentum is wrapped around the anastomosis.

To perform a cervical anastomosis, the esophagus is approached through an oblique left neck incision and stapled at the level of the cricoid. After the gastric conduit is delivered into the neck, the posterior aspect of the conduit and the esophageal stump are juxtaposed maintaining orientation with three stay sutures. A $45 \mathrm{~mm}$ linear stapler is inserted through small gastrotomy and esophagotomy openings, and a delta-shaped posterior anastomosis is performed. The anterior anastomosis is completed with a 4-0 running Maxon suture.

Among the technical pre-requisites for an ideal anastomosis are absence of tension and/or torsion of the gastric tube and an atraumatic technique of handling 
the esophageal stump. Intraoperative assessment of the intramural vascular network of the gastric tube with indocianin green fluorescence may be helpful to select the best anastomotic site on the gastric side, but a quantitative measurement of flow is still lacking. We routinely perform indocyanine green fluorescence angiography before anastomosis in patients previously treated with neo-adjuvant therapy in whom the gastric fundus may have been included in the radiation field (43).

\section{Learning curve, evolution, and impact of new technologies: back to the hand-sewn anastomosis?}

Although centralization of care has improved the overall outcomes of esophageal surgery, the minimally invasive esophagogastric anastomosis has a substantial learning curve, and there is a significant burden of learningassociated morbidity $(44,45)$. A recent international survey found a significant variation in the real-world practice of esophageal surgery, both within and between high and lowvolume units and high-income and low-income countries. A two-stage transthoracic esophagectomy was the most common approach for distal third adenocarcinoma. Circular stapled anastomosis was most commonly performed (47\%), followed by hand-sewn (23\%), stapled side-to-side (13\%), and Orvil (8\%) (46). It has been suggested that existing differences in the details of surgical techniques should be critically shared among experts to identify small incremental changes that may further improve outcomes (47).

The main intrinsic limitations of the classic thoracoscopic approach are the two-dimensional (2D) view and the decreased freedom of movement due to the rigidity of the chest cavity. The role of three-dimensional (3D) optical system for the thoracoscopic approach has been evaluated in a recent pilot study including 13 patients (48). The operation was performed in the prone position and the esophagogastric anastomosis was performed end-toside in two layers with barbed knot-less sutures. Although short-term outcomes were similar, use of the 3D platform in three patients was judged to increased depth perception and enhance visualization. Robotic systems have been introduced to further overcome the limitations of classic thoracoscopy. Interestingly, with robotic esophagectomy, the propensity of surgeons to resume the hand-sewn anastomosis is increasing because of the wrist-like range of motion provided by this new technology $(49,50)$.

\section{Conclusions}

Staplers have reduced the length of operation without increasing morbidity. Although materials and technology have significantly improved, surgeon's experience is still critical and the learning curve should be optimized through well structured training programs. Stapling was initially developed with the aim to standardize the operative technique and to help in difficult anatomical locations such as the upper mediastinum. Paradoxically, with the advent of robotics, the pendulum is swinging back to the handsewn anastomosis. More research is needed to identify the ideal esophagogastric anastomotic technique, but it is likely that morbidity and outcomes are most influenced by other factors such as surgeon's expertise, vascular perfusion of the gastric conduit, the type of endoluminal microbiome, and the quality of perioperative patient's care.

\section{Acknowledgments}

Funding: None.

\section{Footnote}

Conflicts of Interest: The author has completed the ICMJE uniform disclosure form (available at http://dx.doi. org/10.21037/atm.2020.03.66). The author has no conflicts of interest to declare.

Ethical Statement: The author is accountable for all aspects of the work in ensuring that questions related to the accuracy or integrity of any part of the work are appropriately investigated and resolved.

Open Access Statement: This is an Open Access article distributed in accordance with the Creative Commons Attribution-NonCommercial-NoDerivs 4.0 International License (CC BY-NC-ND 4.0), which permits the noncommercial replication and distribution of the article with the strict proviso that no changes or edits are made and the original work is properly cited (including links to both the formal publication through the relevant DOI and the license). See: https://creativecommons.org/licenses/by-nc-nd/4.0/.

\section{References}

1. Goense L, Meziani J, Ruurda JP, et al. Impact of postoperative complications on outcomes after 
oesophagectomy for cancer. Br J Surg 2019;106:111-9.

2. Markar S, Gronnier C, Duhamel A, et al. The impact of severe anastomotic leak on long-term survival and cancer recurrence after surgical resection for esophageal malignancy. Ann Surg 2015;262:972-80.

3. Price TN, Nichols FC, Harmsen WS, et al. A comprehensive review of anastomotic technique in 432 esophagectomies. Ann Thorac Surg 2013;95:1154-60; discussion 1160-1.

4. Okamura A, Watanabe M, Mine S, et al. Factors influencing difficulty of the thoracic procedure in minimally invasive esophagectomy. Surg Endosc 2016;30:4279-85.

5. Kim RH, Takabe K. Methods of esophagogastric anastomosis following esophagectomy for cancer: a systematic review. J Surg Oncol 2010;101:527-33.

6. Schröder W, Raptis DA, Schmidt HM, et al. Anastomotic techniques and associated morbidity in total minimally invasive transthoracic esophagectomy: results from the EsoBenchmark database. Ann Surg 2019;270:820-6.

7. Lewis I. The surgical treatment of carcinoma of the oesophagus with special reference to a new operation for growths of the middle third. Br J Surg 1946;34:18-31.

8. Steichen FM, Ravitch MM. Mechanical sutures in esophageal surgery. Ann Surg 1980;191:373-81.

9. Steichen F. Mechanical sutures in esophageal replacement: fashion or resource? Dis Esophagus 2001;14:1-12.

10. Féketé F, Breil PH, Ronsse H, et al. EEA stapler and omental graft in esophagogastrectomy. Ann Surg 1981;193:825-30.

11. Peracchia A, Bardini R, Asolati M, et al. Mechanical sutures in esophageal surgery. In: Siewert JR, Hölscher AH. editors. Diseases of the esophagus. Berlin: Springer-Verlag, 1988:474-6.

12. Collard JM, Romagnoli R, Goncette L, et al. Terminalized semimechanical side-to-side suture technique for cervical esophagogastrostomy. Ann Thorac Surg 1998;65:814-7.

13. Aiolfi A, Asti E, Rausa E, et al. Use of C-reactive protein for the early detection of anastomotic leak after esophaectomy: systematic review and Bayesian meta-analysis. Plos One 2018; 13:e0209272.

14. Maish MS, DeMeester SR, Choustoulakis E, et al. The safety and usefulness of endoscopy for evaluation of the graft and anastomosis early after esophagectomy and reconstruction. Surg Endosc 2005;19:1093-102.

15. Rausa E, Asti E, Aiolfi A, et al. Comparison of endoscopic vacuum therapy versus endoscopic stenting for esophageal leaks: systematic review and meta-analysis. Dis Esophagus 2018. doi: 10.1093/dote/doy060.
16. Low DE, Alderson D, Cecconello I, et al. International consensus on standardization of data collection for complications associated with esophagectomy: Esophagectomy Complications Consensus Group (ECCG). Ann Surg 2015;262:286-94.

17. Miller RT Jr, Andrus WDW. Experimental surgery of the thoracic esophagus. Bull. Johns Hopkins Hosp 1923;34:109-14.

18. Howes EL, Sooy JW, Harvey SC. The healing of wounds as determined by their tensile strength. JAMA 1929;92:42-5.

19. Postlethwait RW, Weiberg M, Jenkins LB, et al. Mechanical strength of esophageal anastomoses. Ann Surg 1951;133;472-76.

20. Roos D, Dijksman LM, Tijssen JG, et al. Systematic review of perioperative selective decontamination of the digestive tract in elective gastrointestinal surgery. Br J Surg 2013;100:1579-88.

21. Guyton K, Alverdy JC. The gut microbiota and gastrointestinal surgery. Nat Rev Gastroenterol Hepatol 2017;14:43-54.

22. Reddy RM, Weir WB, Barnett $S$, et al. Increased variance in oral and gastric microbiome correlates with esophagectomy anastomotic leak. Ann Thorac Surg 2018;105:865-70.

23. Hyoju SK, Adriaansens C, Wienholts K, et al. Low-fat/ high-fibre diet prehabilitation improves anastomotic healing via the microbiome: an experimental model. Br J Surg 2020;107:743-55.

24. Nagawa H, Seto Y, Nakatsuka T, et al. Microvascular anastomosis for additional blood flow in reconstruction after intrathoracic esophageal carcinoma surgery. Am J Surg 1997;173:131-3.

25. Murakami M, Sugiyama A, Ikegami T, et al. Revascularization using the short gastric vessels of the gastric tube after subtotal esophagectomy for intrathoracic esophageal carcinoma. J Am Coll Surg 2000;190:71-7.

26. Akiyama S, Kodera Y, Sekiguchi H, et al. Preoperative embolization therapy for esophageal operation. J Surg Oncol 1998;69:219-23.

27. Nguyen NT, Langoria N, Sabio A, et al. Preoperative laparoscopic ligation of the left gastric vessels in preparation for esophagectomy. Ann Thorac Surg 2006;81:2318-20.

28. Hölscher AH, Schneider PM, Gutschow C, et al. Laparoscopic ischemic conditioning of the stomach for esophageal replacement. Ann Surg 2007;245:241-6.

29. Sdralis E, Tzaferai A, Davakis S, et al. Reinforcement of intra-thoracic oesophagogastric anastomosis with fibrin sealant (Tisseel@) in oesophagectomy for cancer: a prospective comparative study. Am J Surg 2020;219:123-8. 
30. Gubler C, Vetter D, Schmidt HM, et al. Preemptive endoluminal vacuum therapy to reduce anastomotic leakage after esophagectomy: a game-changing approach? Dis Esophagus 2019;32:doy126.

31. Brown SL, Woo EK. Surgical stapler-associated fatalities and adverse events reported to the food and drug administration. J Am Coll Surg 2004;199:374-81.

32. Kwazneski D, Six C, Stahlfeld K. The unacknowledged incidence of laparoscopic stapler malfunction. Surg Endosc 2013;27:86-9.

33. U.S. Food and Drug Administration. General and Plastic Surgery Devices Panel May 30, 2019 FDA Executive Summary. Available online: https://www.fda.gov/ media/126211

34. Blackmon SH, Correa AM, Wynn B, et al. Propensitymatched analysis of three techniques for intrathoracic esophagogastric anastomosis. Ann Thorac Surg 2007;83:1805-13.

35. Honda M, Kuriyama A, Noma H, et al. Hand-sewn versus mechanical esophagogastric anastomosis after esophagectomy: a systematic review and meta-analysis. Ann Surg 2013;257:238-48.

36. Zhang X, Yu Q, Tian H, et al. Meta-analysis of stapled versus hand-sewn esophagogastric anastomosis. Int J Clin Exp Med 2018;11:11606-18.

37. Luketich JD, Pennathur A, Awais O, et al. Outcomes after minimally invasive esophagectomy: review of over 1000 patients. Ann Surg 2012;256:95-103.

38. Bonavina L, Scolari F, Aiolfi A, et al. Early outcome of thoracoscopic and hybrid esophagectomy: propensitymatched comparative analysis. Surgery 2016;159:1073-81.

39. Maas KW, Biere SS, Scheepers JJ, et al. Minimally invasive intrathoracic anastomosis after Ivor Lewis esophagectomy for cancer: a review of transoral or transthoracic use of staplers. Surg Endosc 2012;26:1795-802.

40. Bonavina L, Asti E, Sironi A, et al. Hybrid and total minimally invasive esophagectomy: how I do it. J Thorac Dis 2017;9:S761-72.

Cite this article as: Bonavina L. Progress in the esophagogastric anastomosis and the challenges of minimally invasive thoracoscopic surgery. Ann Transl Med 2021;9(10):907. doi: $10.21037 /$ atm.2020.03.66
41. Salih AEA, Bass GA, D'Cruz Y, et al. Extending the reach of stapled anastomosis with a prepared OrVilTM device in laparoscopic oesophageal and gastric cancer surgery. Surg Endosc 2015;29:961-71.

42. Knight BC, Rice SJ, Devitt PG, et al. Proximal anastomosis using the OrVilTM circular stapler in major upper gastrointestinal surgery. J Gastrointest Surg 2014;18:1345-9.

43. Goense L, van Rossum PS, Ruurda JP, et al. Radiation to gastric fundus increases the risk of anastomotic leakage after esophagectomy. Ann Thorac Surg 2016;102:1798-804.

44. Schmidt HM, Gisbertz SS, Moons J, et al. Defining benchmarks for transthoracic esophagectomy: a multicenter analysis of total minimally invasive esophagectomy in low risk patients. Ann Surg 2017;266:814-21.

45. van Workum F, Stenstra MHBC, Berkelmans GHK, et al. Learning curve and associated morbidity of minimally invasive esophagectomy: a retrospective multicenter study. Ann Surg 2019;269:88-94.

46. Charalabopoulos A, Lorenzi B, Kordzadeh A, et al. Role of 3D in minimally invasive esophagectomy. Langenbecks Arch Surg 2017;402:555-61.

47. Oesophago-Gastric Anastomosis Study Group on behalf of the West Midlands Research Collaborative. International variation in surgical practices in units performing oesophagectomy for oesophageal cancer: a unit survey from the Oesophago-Gastric Anastomosis Audit (OGAA). World J Surg 2019;43:2874-84.

48. Halliday LJ, Doran SLF, Sgromo B, et al. Variation in esophageal anastomosis technique-the role of collaborative learning. Dis Esophagus 2020;33:doz072.

49. Huang L, Onaitis M. Minimally invasive and robotic Ivor Lewis esophagectomy. J Thorac Dis 2014;6:S314-21.

50. van Boxel G, van Hillegersberg R, Ruurda J. Outcomes and complications after robot-assisted minimally invasive esophagectomy. J Vis Surg 2019;5:21. 